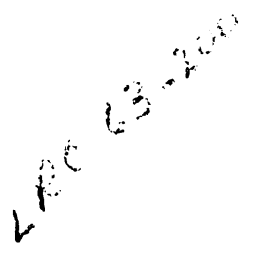

$\lambda$

\title{
A Portfolio of Experience in Refractory Metal Protective Systems Research
}

\author{
11 MARCH 1963

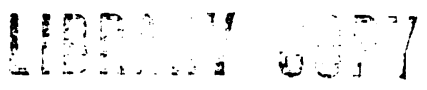 \\ Prepared by D. H. LEEDS \\ Materials Sciences Laboratory

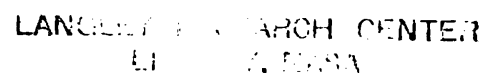 \\ Prepared for COMMANDER SPACE SYSTEMS DIVISION \\ UNITED STATES AIR FORCE \\ Inglewood, California
}

